\title{
Pendampingan dan Pelatihan Media Buku Saku oleh Kader Sebagai Motivator Keberhasilan Pemberian ASI Eksklusif pada Ibu Rumah Tangga
}

\author{
Anjar Astuti ${ }^{1}$, Krisdiana Wijayanti $^{2}$, Emi Murniati $^{3}$, Herlina Tri Damailina ${ }^{4}$ \\ ${ }^{1,2}$ Prodi Kebidanan Blora Poltekkes Kemenkes Semarang \\ ${ }^{3}$ Prodi Teknik Radiodiagnostik dan Radioterapi Poltekkes Kemenkes Semarang \\ ${ }^{4}$ Prodi Kebidanan Magelang Poltekkes Kemenkes Semarang \\ *E-mail : anjarastuti99@gmail.com
}

DOI: https://doi.org/10.21107/pangabdhi.v6i2.7561

Naskah diterima 9 Juli 2020, Revisi 7 September 2020, Terbit 29 Oktober 2020

\begin{abstract}
Abstrak
Cakupan pemberian ASI Eksklusif di Indonesia masih rendah, diantaranya disebabkan rendahnya pengetahuan ibu dan kurangnya kesadaran. Peran kader dalam kesehatan yaitu sebagai pelaku penggerakan masyarakat dalam peningkatan kesehatan ibu bayi. Masalah yang dialami kader yaitu kurangnya pengetahuan dan cara untuk melakukan monitoring pemberian ASI Eksklusif pada ibu menyusui. Media buku saku sebagai motivator keberhasilan pemberian ASI pada ibu rumah tangga dan dapat digunakan untuk meningkatkan pengetahuan kader. Tujuan pengabmas ini adalah untuk meningkatkan pengetahuan kader serta dapat digunakan untuk memonitoring pemberian ASI secara Ekslusif. Sasaran pada pengabdian masyarakat ini adalah ibu kader di Desa Sidomulyo yang berjumlah 37 orang. Pelaksanaan pengabdian masyarakat di lakukan di desa Sidomulyo. Kegiatan yang dilakukan adalah melakukan pelatihan dan pendampingan kepada para kader dalam penggunaan buku saku sebanyak 2x pertemuan serta pembentukan kader sang motivator ASI Eksklusif. Evaluasi dilakukan pada hari ke-2 pengabmas dengan tes pengetahuan dan praktek melakukan monitoring pemberian ASI Eksklusif. Monitoring pengabmas dilakukan setiap bulan selama 3 bulan saat posyandu. Hasil : uji paired t-test menunjukkan bahwa ada perbedaan pengetahuan sebelum dan sesudah pelatihan dengan nilai signifikan $\mathrm{p}=0.000(\mathrm{p}<0.05)$ dan ada perbedaan ketrampilan kader sebelum dan sesudah pelatihan $\mathrm{p}=0.000 \quad(\mathrm{p}<0.05)$. Simpulan : Ada peningkatan pengetahuan dan ketrampilan kader dalam memonitoring pemberian ASI Eksklusif. Saran: kegiatan pengabmas bisa dilaksanakan secara kontinue agar kader dapat memberikan kontribusi langsung kepada masyarakat dalam memotivasi ibu untuk menyusui secara Eksklusif dan memonitoring pemberian ASI Eksklusif sehingga ibu menyusui sukses memberikan ASI Eksklusif kepada bayinya.
\end{abstract}

Kata Kunci: keripik kacang, excel, pencatatan penjualan

\section{PENDAHULUAN}

Salah satu indikator yang menggambarkan kesejahteraan status kesehatan masyarakat suatu negara adalah rendahnya angka kematian bayi (AKB). Salah satu faktor yang berperan dalam tingginya AKB di Indonesia adalah gizi buruk dan diare. Hal tersebut dapat diatasi, diantaranya dengan pemberian ASI pada bayi secara eksklusif (Prasetyani, 2012). Pada riset yang dilakukan oleh UNICEF menjelaskan bahwa kematian sekitar 30 ribu anak Indonesia setiap tahun dapat dicegah melalui pemberian ASI secara eksklusif selama enam bulan sejak kelahiran bayi (Roesli, 2008). Bayi yang diberikan susu formula memiliki kemungkinan meninggal dunia 25 kali lebih tinggi daripada bayi yang diberikan ASI Ekslusif (Selasi, 2009).

ASI merupakan hak setiap bayi yang harus dipenuhi oleh ibunya. Setiap ibu harus memberikan ASI kepada bayinya secara eksklusif sampai bayi berumur 6 bulan tanpa makanan/minuman tambahan apapun. Hal tersebut juga direkomendasikan oleh WHO karena ASI Eksklusif merupakan nutrisi alamiah terbaik bagi bayi dengan kandungan gizi yang paling optimal untuk pertumbuhannya serta menurunkan mortalitas dan morbiditas pada bayi. ASI eksklusif mempunyai manfaat yang besar bagi kelangsungan hidup bayi, tetapi cakupan 
pemberian ASI eksklusif di dunia dan di Indonesia masih rendah (Hegar et.al, 2008).

Menurut WHO ada 10 langkah keberhasilan dalam menyusui, dimana langkah tersebut akan mempengaruhi keberhasilan dalam memberikan ASI secara Eksklusif. Sepuluh langkah tersebut diantaranya adalah adanya kebijakan dari rumah sakit untuk mendukung para ibu menyusui dan tidak mempromosikan susu formula bayi,botol atau dot; tenaga kesehatan rumah sakit yang kompeten sehingga dapat mengajarkan ibu tehnik menyusui yang benar; melakukan IMD pada setiap bayi yang baru lahir, adanya kebijakan di pelayanan kesehatan untuk melakukan rooming in dan membantu memberikan solusi pada setiap masalah ibu yang berhubungan dengan laktasi (WHO, 2014).

Cakupan pemberian asi ekslusif yang masih rendah tidak hanya terjadi pada ibu yang bekerja saja tetapi juga pada ibu rumah tangga (tidak bekerja). Pada penelitian Bahryah (2017) menyatakan bahwa dari 115 sampel ibu rumah tangga hanya $52(32,4 \%)$ yang menyusui secara eksklusif lebih sedikit dibandingkan ibu rumah tangga yang tidak menyusui secara eksklusif, yaitu sebanyak $63(67,6 \%)$. Seharusnya semua ibu rumah tangga dapat memberikan ASI secara eksklusif, tetapi pada beberapa penelitian yang telah dilakukan tidak semua ibu rumah tangga dapat menyusui secara eksklusif, bahkan prosentase ibu rumah tangga yang menyusui bayinya secara eksklusif lebih sedikit dibandingkan dengan ibu rumah tangga yang tidak menyusui bayinya secara eksklusif.

Masih rendahnya cakupan keberhasilan pemberian ASI eksklusif pada ibu rumah tangga dipengaruhi oleh banyak hal, diantaranya adalah rendahnya pengetahuan dan kurangnya informasi pada ibu dan keluarga mengenai pentingnya pemberian ASI eksklusif. Pada penelitian yang telah dilakukan tentang factor factor apa saja yang menghambat pemberian ASI Eksklusif pada ibu rumah tangga, memberikan hasil bahwa factor yang paling dominan adalah masih rendahnya pengetahuan ibu rumah tangga terhadap ASI Eksklusif. Ibu rumah tangga yang mempunyai pengetahuan baik tentang ASI Eksklusif lebih sedikit dibandingkan ibu rumah tangga dengan tingkat pengetahuan yang kurang tentang ASI Eksklusif. Peran kader dalam kesehatan yaitu sebagai motivator keberhasilan pemberian ASI Eksklusif pada ibu rumah tangga dengan cara memberikan pengetahuan kepada ibu menyusui dan memonitor pemberian ASI Ekskusif.

Masalah yang dialami kader yaitu kurangnya pengetahuan dan kurang paham dalam melakukan monitoring pemberian ASI Eksklusif. Media buku saku sebagai motivator keberhasilan pemberian ASI Eklusif pada ibu rumah tangga dapat digunakan untuk meningkatkan pengetahuan dan memotivasi ibu agar sukses menyusui secara Eksklusif.

Hal ini mendorong Prodi DIII Kebidanan Blora Poltekkes Kemenkes Semarang untuk melaksanakan kegiatan Pengabdian kepada Masyarakat (Pengabmas) berupa pendampingan dan pelatihan media buku saku oleh kader sebagai motivator keberhasilan pemberian ASI Eksklusif pada ibu rumah tangga di Desa Sidomulyo Kecamatan Banjarejo Kabupaten Blora, sebagai bentuk dukungan terhadap program pemerintah di bidang kesehatan dan perwujudan Tri Dharma Perguruan Tinggi. Tujuan kegiatan pengabdian in adalah meningkatkan pengetahuan dan ketrampilan kader dalam memberikan pengetahuan kepada ibu menyusui tentang ASI Eksklusif dan memotivasi ibu menyusui agar sukses ASI melalui monitoring pemberian ASI Eksklusif.

\section{METODE}

Metode yang digunakan pada pengabmas ini adalah pemberian edukasi. Sasaran pada pengabdian pengabmas ini adalah kader dengan jumlah 37 orang di Desa Sidomulyo Kecamatan Banjarejo Kabupaten Blora. Syarat peserta pelatihan: aktif menjadi kader minimal 2 tahun, bisa membaca menulis, komunikatif.

Kegiatan pengabdian masyarakat diawali dengan membuat buku saku untuk kader dan melakukaan koordinasi dengan bidan desa. Melaksanakan kegiatan pengabmas sebanyak $2 \mathrm{x}$ pertemuan. Pertemuan yang pertama dilakukan pada tanggal 5 September 2019. Kegiatan pada pertemuan pertama adalah mengadakan pretest, penyampaian materi ASI Eksklusif dan membentuk "Kader Sang Motivator ASI Eksklusif". Tugas Kader tersebut adalah membantu bidan memberikan pengetahuan tentang ASI Eksklusif, memotivasi ibu menyusui dan memonitoring agar ibu sukses ASI Eksklusif. Pertemuan kedua dilaksanakan pada tanggal 6 September 2019. Kegiatan pada pertemuan kedua adalah penyampaian materi tentang cara pengisian monitoring pemberian ASI Eksklusif menggunakan media buku saku dan diakhiri 
Tabel 1. Karakteristik Peserta Kegiatan Pengabmas

\begin{tabular}{|l|l|c|c|}
\hline Variabel & $\mathrm{f}$ & $\%$ \\
\hline \multirow{3}{*}{$\begin{array}{l}\text { Tingkat } \\
\text { Pendidikan }\end{array}$} & SMP & 15 & 40.3 \\
\cline { 2 - 4 } & SMA & 21 & 56.7 \\
\cline { 2 - 4 } & Diploma/sarjana & 1 & 3 \\
\cline { 2 - 4 } & Jumlah & 37 & 100 \\
\hline Pekerjaan & IRT & 25 & 67.5 \\
\hline & Petani & 11 & 30 \\
\hline & Swasta & 1 & 2.5 \\
\hline & Jumlah & 37 & 100 \\
\hline Umur & Produktif (15-65 th) & 37 & 100 \\
\hline & Tidak produktif $(<14$ th dan $>66$ th) & 0 & 0 \\
\hline & Jumlah & 37 & 100 \\
\hline Masa Kerja & Baru ( $\leq 3$ tahun) & 13 & 35.1 \\
\hline & Lama (>3 tahun) & 24 & 64.9 \\
\hline & Jumlah & 37 & 100 \\
\hline
\end{tabular}

dengan post-test. Evaluasi dilakukan pada hari ke-2 pengabmas dengan tes pengetahuan dan cara pengisian monitoring pemberian ASI Eksklusif menggunakan media buku saku. Monitoring dilakukan setiap bulan selama 3 bulan saat kegiatan posyandu.

\section{HASIL DAN PEMBAHASAN \\ Karakteristik Peserta}

Pendidikan terbanyak pada responden adalah SMA $56.7 \%$. Seorang yang memiliki pendidikan formal yang tidak terlalu tinggi belum tentu tidak mampu dibandingkan dengan orang yang lebih tinggi pendidikan formalnya. Namun, faktor tingkat pendidikan turut menentukan mudah tidaknya menyerap dan memahami pengetahuan yang diperoleh. Pekerjaan rata-rata responden IRT sebanyak kelompok $67.5 \%$. Adanya pekerjaan lain tentu akan membuat kader posyandu harus mampu mengalokasikan waktu sebaik mungkin untuk kegiatan posyandu dan pekerjaannya (Simanjuntak, 2012).

Kelompok penduduk umur 0-14 tahun dianggap sebagai kelompok penduduk yang belum produktif secara ekonomis dan kelompok penduduk umur 64 tahun ke atas sebagai kelompok yang tidak lagi produktif. Kekuatan fisik seseorang untuk melakukan aktivitas sangat erat kaitannya dengan umur karena bila umur seseorang telah melewati masa produktif, maka semakin menurun kekuatan fisiknya sehingga produktivitasnya pun menurun. Dalam rentang usia produktif kader posyandu dapat lebih mengalokasikan waktunya untuk aktif dalam kegiatan posyandu (Suroyya, 2017).

Masa Kerja responden rata-rata sudah lama
(> 3 tahun) $64.9 \%$. Semakin lama menjadi kader kesehatan diharapkan akan semakin banyak pengalaman serta pengetahuan sehingga diharapkan kader kesehatan dapat melayani masyarakat dengan baik dan lebih profesional. Kader yang memilki masa kerja lebih lama akan memiliki kedekatan yang lebih mendalam dengan masyarakat, karena kader sudah lebih banyak dikenal (Nurhayati, 2013).

\section{Pengetahuan Responden Sebelum dan Sesudah Edukasi}

Tabel 2. Pengetahuan Responden Sebelum dan Sesudah Edukasi

\begin{tabular}{cccccc}
\hline \multicolumn{2}{c}{ Variabel } & \multicolumn{2}{c}{ Sebelum } & \multicolumn{2}{c}{ Sesudah } \\
\cline { 3 - 6 } & & $\mathrm{f}$ & $\%$ & $\mathrm{f}$ & $\%$ \\
\hline Pengeta- & Baik & 7 & 19 & 16 & 43.3 \\
huan & Cukup & 13 & 35.1 & 12 & 32.4 \\
& Kurang & 17 & 45.9 & 9 & 24.3 \\
& Jumlah & 37 & 100 & 37 & 100 \\
\hline Praktek & Baik & 15 & 40.5 & 29 & 78.4 \\
& Kurang & 22 & 59.5 & 8 & 21.6 \\
& Jumlah & 37 & 100 & 37 & 100 \\
\hline
\end{tabular}

Pada Tabel 2 diatas menunjukkan bahwa pengetahuan baik pada sebelum pelatihan hanya $19 \%$ sedangkan setelah pelatihan $43.3 \%$. Ketrampilan kader pada sebelum dan sesudah baik dari $40.5 \%$ menjadi $78.4 \%$.

\section{Uji Beda Pengetahuan dan Praktek Sebelum Sesudah Edukasi}

Berdasarkan Tabel 3 diatas menggunakan uji paired t-test menunjukkan bahwa ada perbedaan pengetahuan sebelum dan sesudah pelatihan dengan nilai signifikan $\mathrm{p}=0.000(\mathrm{p}<0.05)$ dan ada perbedaan praktek kader sebelum dan sesudah pelatihan $\mathrm{p}=0.000 \quad(\mathrm{p}<0.05) . \quad$ Pengetahuan 
seseorang bisa menjadi lebih luas dengan memiliki sumber informasi yang lebih banyak, seseorang akan cenderung untuk mendapatkan informasi, baik dari orang lain maupun dari media massa. Semakin banyak pengetahuan yang dimiliki maka akan mempengaruhi ketrampilan kader. Demikian sebaliknya apabila responden memiliki tingkat pengetahuan yang rendah, akan menghambat perkembangan ketrampilan dalam memperoleh informasi baru (Wawan dan Dewi, 2010).

Tabel 3. Uji Beda Pengetahuan dan Ketrampilan antar Kelompok

\begin{tabular}{clccc}
\hline \multicolumn{2}{c}{ Variabel } & Mean & $\mathrm{n}$ & $\mathrm{p}$ \\
\hline Pengetahuan & Pre-edukasi & 8.35 & 37 & 0.000 \\
& Post- edukasi & 14.16 & 37 & \\
Ketrampilan & Pre-edukasi & 7.80 & 37 & 0.000 \\
& Post-edukasi & 16.87 & 37 & \\
\hline
\end{tabular}

Pendidikan kesehatan merupakan upaya untuk mempengaruhi dan mengajak orang lain baik individu, kelompok, atau masyarakat agar melaksanakan perilaku hidup sehat. Diharapkan melalui pendidikan kesehatan dapat mengubah perilaku masyarakat dari perilaku yang negatif mengarah ke perilaku yang positif. Untuk mencapai perilaku positif terdapat beberapa faktor yang mempengaruhi proses perubahan tersebut, sesuai dengan teori Green (1980 dalam Notoatmodjo, 2012) yaitu predisposing factors, enabling factors, dan reinforcing factors. Selain itu sesuai dengan teori Rogers (1995 dalam Notoatmodjo, 2012), proses perubahan perilaku juga didahului oleh perubahan pengetahuan, perubahan sikap atau persuasi, pengambilan keputusan, sehingga pada akhirnya akan tercapai tahap implementasi dan konfirmasi.

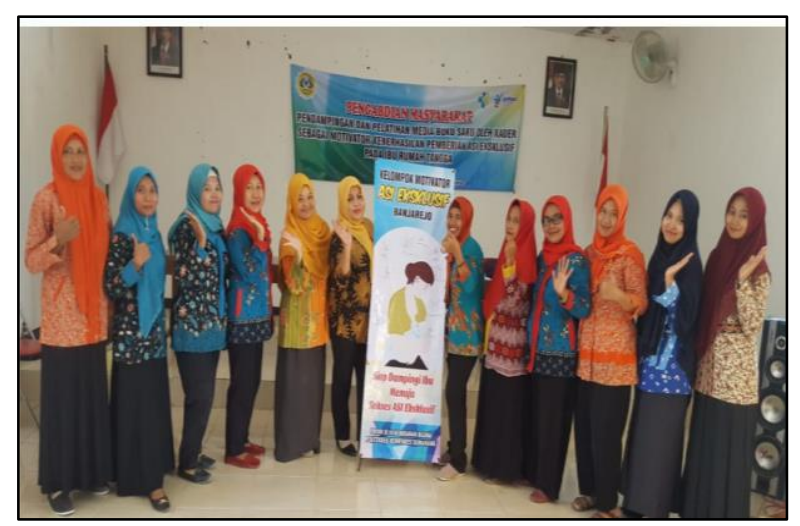

Gambar 1. Peserta Kegiatan Pengabdian Masyarakat

Dari hasil analisis data tentang kegiatan pengabmas didapatkan bahwa pengetahuan dan praktek peserta pengabmas mengalami peningkatan setelah mendapatkan penyuluhan menggunakan metode ceramah dan demonstrasi. Hal tersebut menunjukkan adanya pengaruh yang signifikan berupa peningkatan pengetahuan dan ketrampilan peserta. Sebelum diberikan penyuluhan dengan metode ceramah dan demonstrasi sebagian besar peserta berpengetahuan cukup dan kurang, setelah dilakukan intervensi dalam bentuk ceramah dan demonstrasi terjadi peningkatan pengetahuan yang sangat signifikan, begitu juga dengan ketrampilan kader dalam memotivasi ibu menyusui sukses ASI Eksklusif.

Pengetahuan peserta sebagian besar menjadi pengetahuan baik. Hal ini sejalan dengan penelitian Hidayati, Salawati dan Istiana (2015) yang menyatakan bahwa metode demonstrasi lebih mudah untuk menunjukkan pengertian, ide, dan prosedur tentang suatu hal yang pernah dipersiapkan dengan teliti untuk memperlihatkan bagaimana cara melaksanakan suatu tindakan adegan dengan menggunakan alat peraga.

Ketrampilan kader mengalami peningkatan dari kurang menjadi baik setelah mendapatkan edukasi. Hal ini sejalan dengan penelitian yang dilaksanakan oleh Fatmah dan Nasution (2012) yang menyatakan bahwa ada perbedaan keterampilan responden dengan tingkat cukup dan baik bila dibandingkan sebelum dan setelah pelatihan. Temuan ini juga sejalan dengan penelitian Fitriah (2011) yang melaksanakan studi intervensi bagi kader posyandu balita. Hasilnya menunjukkan adanya peningkatan pengetahuan kader tentang gizi balita sebesar 7 poin setelah diberikan intervensi gizi dan membuktikan pelatihan kader dapat meningkatkan pengetahuan dan keterampilan kader dalam penanggulangan anemia gizi ibu hamil $(\mathrm{p}=0,000)$.

\section{KESIMPULAN}

Pelaksanaan pelatihan sebagai bentuk kegiatan pengabdian masyarakat menunjukkan pengaruh yang positif terhadap pengetahuan dan keterampilan kader dalam memonitoring pemberian ASI Ekslusif.

Saran yang dapat diberikan adalah bahwa buku saku tentang ASI Eksklusif dan cara memonitoring pemberian ASI Ekslusif bisa digunakan sebagai pengayaan bahan ajar untuk meningkatkan informasi baik bagi dosen maupun mahasiswa. Pelatihan pada kader bias terus dilaksanakan untuk memperbaiki dan meningkatkan pelayanan kepada masyarakat 
khususnya pada kegiatan penyuluhan baik untuk ibu maupun anak yang ada di wilayah binaan.

\section{DAFTAR PUSTAKA}

Bahriyah, F., Putri, M. \& Jaelani A.K. 2017. Hubungan Pekerjaan Ibu Terhadap Pemberian ASI Eksklusif Pada Bayi. Journal Endurance. Vol 2 (2). 113-118 pp.

Fatmah, F. \& Nasution, Y. 2012. Peningkatan Pengetahuan dan Keterampilan Kader Posbindu dalam Pengukuran Tinggi Badan Prediksi Lansia, Penyuluhan Gizi Seimbang dan Hipertensi Studi di Kecamatan Grogol Petamburan, Jakarta Barat. Media Medika Indonesia. Vol 46 (2).

Fitriah, Z. 2011. Peran Serta Kader Posyandu dalam Upaya Peningkatan Status Gizi Balita di Posyandu Kelurahan Titi Papan. Ilmu Keperawatan.

Hidayati, A., Salawati, T \& Istiana, S. 2012. Pengaruh Pendidikan Kesehatan Melalui Metode Ceramah dan Demonstrasi Dalam Meningkatkan Pengetahuan Tentang Kanker Payudara dan Ketrampilan Praktik. SADARI. Jurnal Kebidanan Vol 1 (1).

Hegar, et.al. 2008. Bedah ASI Kajian dari
Berbagai Sudut Pandang Ilmiah. Jakarta: Ikatan Dokter Anak Indonesia Balai Penerbit FKUI pp.

Nurhayati, S., \& Sistiarani, C. 2013. Faktor Yang Mempengaruhi Peran Kader Dalam Penggunaan Buku Kesehatan Ibu dan Anak. KEMAS: Jurnal Kesehatan Masyarakat. Vol 8 (2).

Notoatmodjo, S. 2012. Promosi Kesehatan dan Ilmu Perilaku. PT. Rineka Cipta. Jakarta.

Prasetyani, A.E. 2012. Kesehatan Ibu dan Anak (KIA) Dalam Millenium Development Goals (MDGs). Yogyakarta: Nuha Medika.

Roesli, U. 2008. Inisiasi Menyusu Dini Plus ASI Eksklusif. Jakarta: Pustaka Bunda.

Simanjuntak, M. 2012. Karakteristik Sosial Demografi dan Faktor Pendorong Peningkatan Kinerja Kader Posyandu. Jurnal Wira Ekonomi Mikroskil. Vol 2 (1).

Selasi S, 2009. Pelatihan konselor laktasi. Dalam: Roesli, Utami, Laktasi Indonesia. Ed 2. Jakarta, Prima Pustaka: 78-90.

WHO. 2014. Handbook For Guideline Development, 2nd Ed. Geneva: World Health organization 
2 Jurnal Pangabdhi 